Forthcoming in Improvisation: The Competence(s) of Not Being in Control, eds. J. McGuirk, S. Ravn, and S. Høffding. Routledge

\title{
Towards a wide approach to improvisation
}

Joel Krueger and Alessandro Salice ${ }^{1}$

This paper pursues two main aims. First, it distinguishes two kinds of improvisation: expert and inexpert. Expert improvisation is a (usually artistic) practice that the agent consciously sets as their goal and is evaluated according to (usually artistic) standards of improvisation. Inexpert improvisation, by contrast, supports and structures the agent's action as it moves them towards their (usually everyday life) goals and is evaluated on its success leading the agent to the achievement of those goals. The second aim is to describe inexpert improvisation as a robustly distributed affair, one that involves the ongoing integration of embodied practices with social and material resources within our surrounding environments. On the wide approach to improvisation fostered in this paper, inexpert improvisation is claimed to be our default way of inhabiting our world.

Keywords: expert improvisation, inexpert improvisation, intention, extended mind, mental institutions

Joel Krueger is Senior Lecturer in the Department of Sociology, Philosophy, and Anthropology at the University of Exeter. He works primarily in phenomenology, philosophy of mind, and philosophy of cognitive science, with a particular focus on issues in $4 \mathrm{E}$ (embodied, embedded, enacted, extended) cognition, including emotions, social cognition, and psychopathology. He also writes about comparative philosophy and philosophy of music. ORCID https://orcid.org/0000-0003-0931-1596

\begin{abstract}
Alessandro Salice is Lecturer at the Department of Philosophy of University College Cork and Research Associate at the Center for Subjectivity Research in Copenhagen. He has extensively published on a variety of topics related to phenomenology, philosophy of mind and action, and moral psychology. His current work mainly addresses issues concerning human sociality. Alessandro is co-editor of Journal of Social Ontology.
\end{abstract}

ORCID https://orcid.org/0000-0002-7255-2889

\footnotetext{
${ }^{1}$ Both authors contributed equally to this work.
} 
Forthcoming in Improvisation: The Competence(s) of Not Being in Control, eds. J. McGuirk, S. Ravn, and S. Høffding. Routledge

\section{Introduction}

Improvisation is sometimes assumed to be a rarefied phenomenon, a species of performative practice that is relatively unique insofar as it requires specialized knowledge, training, skills, and expertise largely confined to a particular domain. ${ }^{2}$ For example, many current discussions focus on skilled improvisation in the context of art (e.g., improvisational dance, theater, freeform jazz improvisations) or athletics (e.g., a basketball player making a spontaneous behindthe-back pass to a teammate as a defender closes in). While these discussions are useful for illuminating some of the experiential and behavioral dynamics distinctive of highly-skilled improvisational practices, they potentially lead us to adopt an excessively narrow focus that overlooks more common - i.e., less specialized - forms of everyday improvisation, or so we claim.

In this chapter, we argue against a narrow approach to improvisation. We challenge this narrow approach in two ways. First, we develop a "wide" perspective that situates improvisation directly within the ebb and flow of everyday life (i.e., and not primarily unique or specialized domains). Second, we argue that a wide perspective highlights the extent to which everyday improvisation is very often a robustly distributed (i.e., beyond-the-head) affair, one that involves the ongoing integration of sensorimotor processes with social and material resources within the artifacts, practices, and institutions that make up everyday life. We conclude that, to fully understand the phenomenon of improvisation, we should enlarge the scope of analysis and shift attention from expert improvisation (which has narrow relevance in our daily life) to inexpert improvisation (which, by contrast, is a pervasive phenomenon in our lives).

We develop our wide perspective in several steps. First, we start by distinguishing between everyday (i.e., inexpert) and expert improvisation. To begin with the latter: when an action is based on expert improvisation, improvisation is the goal of the action - or more precisely, improvisation is a proximate goal of the action, in contradistinction to the action's distal goal (we come back to this distinction in the next section). Improvisation, that is, is part of the conditions of satisfaction of the intention that steers the action. Accordingly, to perform an

\footnotetext{
${ }^{2}$ We discuss some reasons for this assumption and how it has informed treatments of improvisation within certain disciplinary quarters in section 2 .
} 
Forthcoming in Improvisation: The Competence(s) of Not Being in Control, eds. J. McGuirk, S. Ravn, and S. Høffding. Routledge

action in an expertly improvised way is one specific way of performing the action, and the success of the action will be assessed depending, among other things, on whether and how the action's (proximate) goal (i.e., improvisation) has been achieved. In contrast, inexpert improvisation is not part of the intention's conditions of satisfaction and, hence, is not a way of performing the action. Rather, inexpert improvisation could be seen as a set of processes - e.g., trial and error strategies, action monitoring and prediction, motor imagery, etc. (as we will see, some of which are distributed) - the outcome of which is to support and structure the agent's action as it moves her towards her goal. In this case, too, the success of the action will be assessed depending on whether and how the goal has been achieved. However, the key difference between expert and inexpert improvisation is that, for the latter, improvisation is neither a proximate nor a distal goal of the action.

In the second step, we corroborate this conceptual distinction by highlighting the extent to which everyday inexpert improvisation is very often a robustly distributed affair, one that involves the ongoing integration of embodied practices with social and material resources within our surrounding environments. Inexpert improvisation is, we argue, constitutive of our default way of inhabiting our world. This is because as embodied and situated subjects, we are continually adapting in real-time to the ongoing — and often unpredictable — flow of forces and feedback we receive from the people, things, and spaces around us. In other words, we are continually determining what to do now based on how the world is now - an improvisational dynamic at the heart of both individual and joint action. We conclude our discussion by briefly considering some broader implications of our wide approach to improvisation.

\section{Identifying two forms of improvisation}

We begin by distinguishing two forms of improvisation: inexpert improvisation and expert improvisation. We underpin this distinction by developing a series of considerations about intentional actions, intentions, and goals. This section draws a conceptual distinction which is then underpinned by the empirical observations made in section 2 . 
Forthcoming in Improvisation: The Competence(s) of Not Being in Control, eds. J. McGuirk, S. Ravn, and S. Høffding. Routledge

Some of our actions are intentional in the sense that they are triggered, steered, and monitored by intentions as a specific kind of pro-attitudes. Consider the action of your arm moving up and the action of you raising your arm. Although these two events, in principle, might be indiscernible from an external observer's perspective, they clearly differ from each other. Notoriously, this observation led Wittgenstein to raise the question as to what marks the difference between these two actions (Wittgenstein 1958, Sect. 621). Part of the answer to this question, it can be contended, has to do with the fact that the second, but not the first, action has been caused and was controlled by an intention of the agent.

Interestingly, the notion of intention comes in different forms. In this paper, we are mainly interested in so-called "prior intentions", which is an expression that roughly maps onto the sense of the more colloquial term 'decisions' (see Salice 2018 in relation to the following description of prior intentions, which largely relies on the works of Bratman, Gilbert, and Searle). If understood in this sense, the intention is that mental act which brings a process of deliberation to an end. In deliberation, the agent is confronted with different options for their future conduct and, by forming the intention, the agent settles on one of those options. The agent thereby commits herself to that conduct. This aspect distinguishes prior intentions from desires, which are not infused by a commitment and therefore wax and wane in time. This commitment also enhances stability in the future actions of an agent insofar as it puts the agent under the pressure of planning their actions in such a way as to enable the satisfaction of the prior intention. This allows the identification of another difference between intentions and desires: intentions are "causally self-reflexive" attitudes in the sense that, for them to be satisfied, they require that the very intention plays a causal role in its satisfaction. So, for instance, if at the end of high school Pam ponders which career to pursue and she decides to become an academic, her intention will be satisfied if it is causally active in bringing about the state of affairs of Pam's being an academic. By contrast, desires are not causally selfreflexive: if your desire is to become rich, then inheriting money from a dead relative will satisfy your desire even though your desire played no causal role in bringing about that state of affairs.

Prior intentions are attitudes with a world-to-mind direction of fit: they represent the world in a certain manner and the attitude is satisfied only if the world complies with that representation. When Pam has decided to become an academic, then her intention will be 
Forthcoming in Improvisation: The Competence(s) of Not Being in Control, eds. J. McGuirk, S. Ravn, and S. Høffding. Routledge

satisfied if she manages in bringing about the state of affairs of Pam's being an academic. That state of affairs, as the outcome of her action, is the condition of satisfaction of her intention. Sometimes, the outcome of an action (which typically does not exist at the moment in which the agent has made a decision) is called "the goal" in the relevant literature (Butterfill 2013). ${ }^{3}$ In this paper, we prefer a different terminological usage: we will call the "goal of an agent" the representation this agent has of the world when they form an intention. ${ }^{4}$ The goal that Pam's intention specifies is the representation of the intention's conditions of satisfaction: to become an academic. If the outcome of her action matches the way she has represented the world in her intention, then the intention is satisfied. Our terminological postulation nicely squares with the way in which we sometimes talk about goals: "satisfying”, "reaching” or "achieving one's goal" are expressions which are at least compatible with our understanding of a goal. Importantly, we can distinguish between proximate and distal goals. Imagine Pam sets for herself the distal goal to become an academic. In order to achieve this (distal) goal, several other goals, i.e., proximate goals, must first be achieved first. For instance, Pam could decide to publish her $\mathrm{PhD}$ dissertation. This is a proximate goal, which serves the realization of her distal goal. Had Pam, by contrast, decided to reach her distal goal by publishing several papers (rather than a single book), then her proximate goal would be different from the one in the previous scenario but her distal goal would remain the same.

The picture that emerges is therefore one in which, by forming one's intention, i.e., by setting one's goal, the agent also indicates some criteria of evaluation of their action. One could say that prior intentions set certain standards for an agent's success. If the action is such that it brought about an outcome which corresponds to the agent's goal, then the action should be evaluated positively. By contrast, if the action is such that it did not bring about an outcome corresponding to the agent's goal, then the action should be evaluated negatively. This holds for both proximate and distal goals. Suppose, once again, that Pam decides to have an academic career by publishing her $\mathrm{PhD}$ dissertation. Eventually, she reaches her proximate but not her distal goal; while she publishes her dissertation, other factors prevent her from becoming an academic. In this case, something has obviously gone wrong in her plan. The

\footnotetext{
${ }^{3}$ According to a different terminological use, "goals" are conative states of a particular kind-different from desires and from intentions (Bratman 2014).

${ }^{4}$ We remain neutral on whether "representation" is a mental state or the content (in opposition to the object) of a mental state as nothing in our paper hinges on this issue.
} 
Forthcoming in Improvisation: The Competence(s) of Not Being in Control, eds. J. McGuirk, S. Ravn, and S. Høffding. Routledge

same can be said if the converse happens: she becomes an academic but without publishing her dissertation. Even though the degree of failure is certainly milder if compared with the previous scenario, something has, once again, gone wrong in her original plan.

At this stage, it is important to briefly touch upon an important and complex issue - one that will have direct bearing on the discussion below. This is the idea that the agent, when forming their intention, might not have complete practical knowledge on how to reach their goal. To go back to our example, it is highly likely that at the moment in which Pam decides to become an academic, she won't have access to all of the knowledge one needs in order to become an academic. Of course, one could suppose that, as time passes, she will be accumulating knowledge of what is required of her to reach that goal (how to give a talk, how to write a paper, how to network with her peers etc.). For now, we do not need to further elaborate on the notion of practical knowledge. For this brief characterization can already put us in a position to identify a first sense of the term "improvisation". Since Pam's actions towards the goal are steered by insufficient practical knowledge (however this notion should be defined more precisely), she will improvise: we call this form of improvisation inexpert improvisation.

Three comments are in order on inexpert improvisation. First, it is highly likely that improvisation in this first sense just is an umbrella notion for several different strategies the agent will activate to reach her goal. Trial and error, quick heuristic, imitation of others and their actions, etc. are all strategies that seem to fall within this broad category (some of these processes and strategies will be investigated in the next section). The second comment relates to the idea that inexpert improvisation does not apply only to diachronically extended agency serving significant life-decisions, as in the case of Pam's deciding to become an academic; short-lived and everyday actions may be called "improvised" in the very same sense (we discuss many more examples of everyday improvisation below). For example, suppose that you decide the time has finally come to fix your clogged tap — but you have no expertise in this area whatsoever. In order to fix the tap, you will therefore have to improvise in the sense at stake: e.g., fiddle with the tap to get a sense of how it's constructed; watch some YouTube videos; use duct tape or nuts and bolts to craft a makeshift wrench upon realizing you don't have the appropriate tools for the job. Another way of reporting what you are doing in this scenario is by saying that, because you don't know how to fix the tap, you are trying to fix 
Forthcoming in Improvisation: The Competence(s) of Not Being in Control, eds. J. McGuirk, S. Ravn, and S. Høffding. Routledge

the tap (where the verb 'trying' captures the notion of inexpert improvisation at stake here). Finally, improvisation will be evaluated only based on instrumental values, that is, based on its capacity to enable the agent to reach their goal. If you end up fixing your tap, then your improvisation was successful (for that task at stake). Analogously, if Pam survives the hellish phase of an early academic career, then her improvisation was successful (for the task she has set for herself). What is important, however, is that improvisation is not a proximate goal serving the achievement of the distal goal: the agent did not decide to fix the tap by improvising or to achieve an academic career by improvising. To put this differently, the agent is thematically focused only on reaching their goal (fixing the tap), not on improvisation itself.

These comments put us in the position to introduce the second sense of improvisation. Let us start with the idea that, whereas inexpert improvisation is something that the agent standardly is forced to adopt in order to reach a goal that she is unsure how to reach, expert improvisation is something that is deliberately envisioned by an agent. More precisely, improvisation is something that an agent can set as their goal. The agent, that is, may decide to perform an action which is, in its essence, improvised. Accordingly, it can be claimed that expert improvisation itself (in contrast to inexpert improvisation) is something the agent is thematically aware of. Further comments are in order. First, we conjecture that the second sense of improvisation is most frequently found in art practices: dance, literature, painting, theatre, music, etc. Second, we again conjecture that, just as for inexpert improvisation, the label of "expert improvisation" encompasses different phenomena and, specifically, different practices. Third, it seems sensible to claim that, in these practices, expert improvisation usually is a proximate goal which is supposed to enable achievement of a distal goal (such as a striking, moving, or intense performance, or triggering an aesthetic experience in the audience, etc). ${ }^{5}$

Based on the last comment, the relation between trying to fix the tap and fixing the tap may appear as analogous to the relation between engaging in improvised dance and, say, triggering an aesthetic experience in an audience. However, one should not overlook the

\footnotetext{
${ }^{5}$ We consider as an ultimately empirical question whether expert improvisation can only stand in a proximate position or whether it can also be put in a distal position - see below.
} 
Forthcoming in Improvisation: The Competence(s) of Not Being in Control, eds. J. McGuirk, S. Ravn, and S. Høffding. Routledge

following, and essential, difference: when it comes to inexpert improvisation, we claimed that, it is because the agent does not know how to fix the tap that they try to do that. By contrast, in the case of expert improvisation, the agent does very well know how to deliver a striking performance and this precisely is by way of (expertly) improvising. In this form of improvisation, that is, the agent is not trying to deliver a striking performance, at least not in the same sense in which, you can only try to reach a goal, if you don't know how to reach it.

Now, we have seen that inexpert improvisation is evaluated based on its effectiveness in reaching the agent's goal. How, then, should expert improvisation be evaluated? Since expert improvisation is something that the agent sets as a goal for herself (regardless of whether this is a proximate or a distal goal), it cannot be evaluated in the same way in which inexpert improvisation is evaluated. Remember: inexpert improvisation, it has been claimed, is never a goal in itself. The value of inexpert improvisation, as it were, is entirely instrumental and extrinsic. We engage in inexpert improvisation only to reach a (proximate or distal) goal.

By contrast, expert improvisation has intrinsic value. This is certainly the case when expert improvisation is the distal goal of an action (we come back to this possibility at the end of this section). But even when inexpert improvisation is a proximate goal in the service of a distal goal, then its instrumental value relies on its intrinsic value. The artist will not deliver a striking, moving, or intense performance and/or s/he will not trigger an aesthetic experience in the audience, unless improvisation carries intrinsic values (these are values that cannot be defined solely in virtue of their instrumental role in reaching another goal).

What are the intrinsic values that characterise expert improvisation? We suggest that these must be defined in relation to the standards of the relevant art practice. An episode of improvised ballet, for instance, would have to be evaluated with reference to the aesthetic criteria defined within that form of art. Equally, a session of improvised jazz would have to be evaluated in relation to the criteria endorsed by that form of art. Accordingly, qualities that specify one form of improvisation as being successful in a particular domain may not apply to another. For example, qualities that specify successful free jazz (e.g., disregarding fixed instrumental roles; dissonance; rejection of fixed harmonic, rhythmic, or melodic structures, etc.) may not work in the context of improvised ballet, where standards of successful improvisation are differently constrained. Whether or not expert improvisation reaches 
Forthcoming in Improvisation: The Competence(s) of Not Being in Control, eds. J. McGuirk, S. Ravn, and S. Høffding. Routledge

excellence entirely depends on the conditions of excellence recognised and acknowledged within the relevant discipline. This indicates that the two forms of improvisation we have distinguished - inexpert vs. expert - are genuinely distinct and that, therefore, they should be clearly set apart by any investigation into improvisation.

Let us conclude this section by highlighting that, of course, there may be occasions where expert and inexpert improvisation may overlap. Let us return to Pam the academic. Imagine that Pam is, for the first time in her life, invited to engage in an improvised dance session. As this is the first time to be confronted with this task, Pam is understandably nervous, but she agrees. Once she accepts the invitation, Pam sets as her goal the realisation of an episode of improvised dance. Note that, in this case, one could contend, improvisation is not in a proximate but in a distal position: Pam has not decided to engage in improvisation to reach other artistic goals, but she made that decision just for the sake of exploring that particular practice. Now, she has made that decision even though she has no clue how to improvise precisely because it is the first time she has tried it. This lack of knowledge is why she will inexpertly improvise in the pursuit of her goal (which is the improvisation itself). ${ }^{6}$ Obviously, this should not be taken as an indication that the forms of improvisation coincide, but rather that they should be disentangled if one is to give an adequate description of these kinds of situations.

Let us take stock. In this section, we have established a conceptual distinction between inexpert and expert improvisation. This provides the basis for our discussion in the remainder of this paper. In the next sections, we will argue that inexpert improvisation is a crucial resource in our daily life, which ought to be appreciated in itself. In appreciating this form of improvisation in itself, i.e., in pointing to some of its main features and characteristics, we will also resist the attempt to restrict the notion of improvisation to expert improvisation tout court as well as the attempt to understand the notion of inexpert improvisation in the light of expert improvisation.

\section{Improvisation in everyday life and beyond the head}

\footnotetext{
${ }^{6}$ A vivid illustration of this possibility has been offered to the authors during several workshops of the Improv networking project (2016-18): during these workshops, professional artists have invited participants to engage in various forms of expert improvisation. The result consisted in several laymen improvising how to expertly improvise.
} 
Forthcoming in Improvisation: The Competence(s) of Not Being in Control, eds. J. McGuirk, S. Ravn, and S. Høffding. Routledge

This section reviews some current work on improvisation to object against the narrow focus that has been usually put on expert improvisation. In doing so, we also provide some examples and empirical evidence to support our conceptual distinction.

It is, perhaps, initially tempting to characterize improvisation as a relatively rare class of actions somehow set apart from the ebb and flow of everyday life. As the British composer and writer Neil Sorrell (1992) observes, part of this assumption comes from how the term is used in everyday parlance: "The word itself poses all kinds of problems, not only because of its extensive and vague application to music, but also because of its usage in everyday speech, conveying something that is insufficiently prepared and of no lasting value (for example, "an improvised shelter") (p. 776). Call this the "uniqueness assumption" (UA). UA is the idea that improvisation is a temporary and novel form of action distinct from the "normal" (i.e., non-improvised) modes of action that characterize most of our everyday skilled behavior.

UA can be found, for example, within the discourses and techniques that frame how improvisation is theorized and taught within many musical communities in Western pedagogical culture (Torrance \& Schumann, 2019; van der Schyff, 2017). Within these communities, improvisation is thought of as a mode of performance that deviates from normal recitative performance. Musicians are taught to master the skills needed to correctly read and play from notated works of distinguished composers. So, although improvisation was a common feature of European art music well into the nineteenth century, "[t]he current musical culture in Western countries - one in which a highly skilled instrumentalist may be completely incapable of improvising — is historically and culturally unique. Today, in Western cultures, improvisation is almost entirely absent from the high art tradition and, consequently, is almost completely absent from the music education curriculum" (Sawyer, 2007, p. 1). In light of these assumptions, it is therefore not surprising that musicians who've received this classical scripted training often find it challenging to deviate from the printed manuscript when they are invited to experiment and improvise (Torrance \& Schumann, 2019, p. 259). ${ }^{7}$

\footnotetext{
${ }^{7}$ See Shiavio and Hoffding (2019) for an extended treatment of musicking, across a range of different domains, that portrays musicking as fundamentally a creative and improvisatory exploration of both music and the bodily and social self.
} 
Forthcoming in Improvisation: The Competence(s) of Not Being in Control, eds. J. McGuirk, S. Ravn, and S. Høffding. Routledge

In addition to UA, there is a second assumption found in the improvisation literature also relevant to our concerns here. It is that improvisation is largely a head-bound affair insofar as it requires specialized knowledge, skills, and training that are unique to, and realized within, the head of the individual. Call this the "head-bound assumption" (HBA). HBA is motivated by a tendency (which, as we'll see, is not entirely unfounded) to see improvisation as a form of creativity requiring the possession of different forms of knowledge. Accordingly, as Linson and Clarke observe, "[i]ntuition might suggest that creativity and cognition must originate in the mind of an individual (after all, our thoughts, insights and new discoveries seem to occur in our own heads)" (Linson \& Clarke, 2017, p. 54). We find HBA made explicit in the work of some anthropologists and psychologists. They portray the knowledge and skills needed for creativity and improvisation as emerging from prototypical schemas or "memes" - information-bearing modules that have been copied into an individual's head by prior processes of replication (Aunger, 2000; Sperber, 1996). As Ingold and Hallam (2007) observe, for this meme-theory approach, these modules "are supposed to inhabit the mind as genes inhabit the body, whenever they control that carrier's thought and behaviour" (p.6). To understand the origin and character of improvisation, therefore, primarily requires focusing on things going on inside the head of the individual.

The wide perspective we advocate here challenges both UA and HBA and argues for a different way of thinking about improvisation and its place in our lives. From this perspective, improvisation is an essential part of our day-to-day activities - no matter how mundane or familiar. In fact, a closer look suggests that we improvise more often than we follow a fixed script; the latter is the rarer class of action than the former. Improvisation is therefore arguably our default way of being-in-the-world, a central feature of both individual and collective action. To use our terminology, most of our everyday actions consist (at least partially) of inexpert improvisation. This is because the goal of our everyday improvisation is generally not the improvisation itself; our acts of improvisation serve, rather, as a means toward some further end, a way of coping with an unpredictable and continually changing world. They consist of a suite of strategies, enacted over both short and long-term timescales, that we use to reach our goal: again, things like trial and error, quick heuristic, imitation of others and their actions, etc. And as we'll see, these strategies are often dynamically driven 
Forthcoming in Improvisation: The Competence(s) of Not Being in Control, eds. J. McGuirk, S. Ravn, and S. Høffding. Routledge

and regulated, in an ongoing way, by norm-governed artifacts and institutions that lie beyond individual heads.

\subsection{Improvisation in everyday life}

To make these points clearer, let us first consider how central improvisation is to some common everyday activities. Writing things on paper, for example, might initially seem to be a relatively straightforward activity that leaves little room for improvisation. When writing, we generally know what we want to say and how we want to say it. And we do so by drawing upon skills that have been trained over many years to render the "correct" form of the numbers and letters we write. However, as Ingold and Hallam (2007) observe, "there is no script for script" (p.13). The activity of writing involves making fine adjustments in response to monitoring the conditions of the task as it unfolds: the feel of the pen, the flow of the ink, the resistance of the paper, developing muscle cramps, changes in the ambient lightning, etc. Moreover, even when working within the formal constraints of writing, rendering a line on the paper is an ongoing act of gestural improvisation (ibid., p.13); an individual's handwriting is, perhaps, as distinctive as their voice. This is because writing is more than simply a means of communication. It is "oneself on paper" (Sassoon, 2000, p. 103) - a creative act of self-expression that emerges through many years of experimentation and improvisation.

Next, consider another straightforward example: going for a walk to get some fresh air. Taking a walk can be a relatively long process depending upon one's intentions and stamina. But it also consists of ongoing acts of moment-to-moment "micro-improvisations", as we might term them. When we first set out, we may not initially know where we're going but instead simply arbitrarily start walking in one direction instead of the other as we reach the end of our driveway; we might amble slowly before later picking up the pace as our muscles start to warm up; bored of this side of the road, we cross to the other for a better view; we step nimbly over cracks; suddenly duck down a side road to avoid a chatty neighbor; pause to gaze with admiration at a well-manicured garden; catch our balance after stumbling over an uneven portion of the sidewalk, etc. 
Forthcoming in Improvisation: The Competence(s) of Not Being in Control, eds. J. McGuirk, S. Ravn, and S. Høffding. Routledge

Opportunities for improvisation frequently arise in everyday life because things often go wrong or arise unexpectedly. Responding to the unexpected and recalibrating our actions and expectations accordingly is, as Dewey observes, the basis of learning - a perpetual movement from disequilibrium (confusion, doubt, uncertainty) toward equilibrium (satisfaction, knowledge) (Dewey, 1934/1980). Imagine you step awkwardly during your neighborhood walk and badly sprain your ankle. Suddenly, much has changed - beyond the obvious fact of your physical injury. Your relationship to the environment as a whole has been thrust into a state of disequilibrium. This is because you can no longer rely upon the skills, habits, and powers that were previously taken for granted (e.g., the ability to move freely and without pain). A quiet tree-lined street that previously afforded pleasant walking is now experienced as a foreboding environment. So, you must improvise. You might hobble up to a nearby doorstep and ask for assistance; call for help using your mobile phone; lean on the bumper of a nearby car for some temporary relief as you plot your next move; signal to construction workers across the street that you need help; use a nearby fallen tree branch as a make-shift cane, etc.

The point of these considerations is that our everyday skills and actions are, to use another of Dewey's favored terms, remarkably plastic. When you sprain your ankle, you are forced to suddenly recalibrate how you relate to the environment as a whole and adapt in real-time to a new set of possibilities and constraints. This sort of improvisation does not require completely abandoning old skills, habits, and norms of walking, of course. But it does involve transforming these familiar skills and habits and, in so doing, establishing new norms of successful movement that reflect new ways of improvising and establishing equilibrium with the environment in light of your injury. These acts of improvisation are examples of inexpert improvisation, to use our terminology, because the goal is not the improvisation itself; it is, rather, a means to an end (e.g., getting home to take care of your ankle). Moreover, unless you have medical training or are very familiar with that environment, you may not know, initially, what the best course of action is or what sort of resources are available to you; as the shock wears off and you begin to survey your environment, your actions are steered by insufficient practical knowledge. Again, you must improvise. In addition, improvisation is evaluated solely based on whether it was conducive to the achievement of the goal (it was not evaluated in itself). And crucially for our purposes, the 
Forthcoming in Improvisation: The Competence(s) of Not Being in Control, eds. J. McGuirk, S. Ravn, and S. Høffding. Routledge

form your improvised actions take is specified not only by features of your physical condition (i.e., your sprained ankle) but also by resources present in the environment.

Despite the prominence of UA in some current debates, pragmatists and phenomenologists like Dewey and Merleau-Ponty were deeply attuned both to the centrality of (inexpert) improvisation in everyday action, as well as to the interrelation between the structure of our improvised actions and the norm-governed environments to which they are responsive. In Democracy and Education, for example, Dewey tells us that "the environment consists of those conditions that promote or hinder, stimulate or inhibit, the characteristic activities of a living being" (Dewey, 2008, p. 15). Moreover, his concept of "plasticity" - the adaptive quality by which individuals "learn to learn" (ibid., p. 50) - captures the extent to which our ability to maintain an equilibrium with our environments rests upon our capacities for openended creativity and improvisation in response to the flow of changes and unexpected developments that are part of everyday life.

Likewise, Merleau-Ponty provides an example in The Structure of Behavior that illustrates how a living thing's capacity for inexpert improvisation — as well as the norms governing the success or failure of these improvisations - is tied to environmental features. He writes:

It has long been known that the dung beetle, after the amputation of one or several phalanges, is capable of continuing its walk immediately. But the movements of the stump which remains and those of the whole body are not the simple perseveration of those of normal walking; they represent a new mode of locomotion. . . Moreover, this reorganization of the functioning of an organ (Umstellung) is not produced unless it is rendered necessary by the nature of the dynamic equilibrium between self and environment surface: on a rough surface where the member, even though shortened, can find points of application, the normal process of walking is conserved; it is abandoned when the animal comes upon a smooth surface (Merleau-Ponty, 1963, pp. 39-40).

Again, the important point, as Laura Mcmahon observes, is that "[i]n "finding its legs" again after a bodily trauma, the dung beetle does not return to a past norm of walking but establishes a new equilibrium with its environment, when, and only when, the environmental 
Forthcoming in Improvisation: The Competence(s) of Not Being in Control, eds. J. McGuirk, S. Ravn, and S. Høffding. Routledge

circumstance calls for it" (McMahon, 2018, p. 615). Like the sprained ankle example above, the insect amputee improvises in relation to its own (altered) capacity for walking and continually changing environmental conditions (rough vs. smooth surface). We will say more about the deep interdependence between inexpert improvisation and environmental resources in the following section.

To further drive home the idea that inexpert improvisation is central to everyday life, consider how even the performance of relatively scripted activities is sustained by how we make use of spaces for improvisation that exist within these scripted activities. While following a recipe, for example, we may spontaneously decide to add a little extra spice because it simply feels right, or improvise a substitute when we realize we're out of a necessary ingredient; we might suddenly feign laughter at a stranger's awkward joke while making small talk at a party; consoling a distraught friend involves calibrating our responses in real-time to what they express and what sort of responses we think will best help them feel better; while standing in a queue, we may stubbornly refuse to move forward until the person behind us backs up and stops crowding our personal space; helping a friend move heavy furniture down a staircase is an ongoing delicate improvisation in response to our friend's movements and the physical limitations of that space. In these cases, we may have reasonably well-formed goals in mind (e.g., cooking a nice dinner; making sure our conversation partner thinks we appreciate their humor; helping our friend work through their sadness; sending a social signal indicating our annoyance at being crowded; getting the furniture where it needs to go). But we may not always know how best to reach these goals given the contingencies of our current situation and/or our lack of relevant practical knowledge. So, we experiment with different strategies along the way until we hit upon those that, given the constraints of our current situation, seem most likely to work.

As we'll soon see, all of the actions mentioned above - including how and where one strolls through the neighborhood for some fresh air (e.g., I don't wander through my neighbors' backyards uninvited) - involve following often-complex sets of social scripts and wellestablished, norm-governed conventions. However, to understand the ontology of these actions, we need to discuss more than just predefined scripts and conventions. This is because, more fundamentally, these actions arise from a real-time responsiveness to physical and social environments that are constantly changing — an improvisational plasticity that is 
Forthcoming in Improvisation: The Competence(s) of Not Being in Control, eds. J. McGuirk, S. Ravn, and S. Høffding. Routledge

both responsive to environmental constraints and which also opens up new possibilities for further action as we adapt to and exploit these constraints (Sutton \& Bicknell, Forthcoming). And the key takeaway point, then, is that "[b]efore and beneath any activity of planfollowing, life is a continual improvisation, a matter of deciding what to do now based on how the world is now" (Agre \& Chapman, 1987, p. 268). Responsivity to this ongoing flow of nows, we suggest, is at the heart of our everyday inexpert improvisation.

\subsection{Improvisation beyond the head}

As part of our wide perspective on improvisation, we have so far challenged UA and argued that improvisation is not a special class of actions but rather something that is situated within the ebb and flow of everyday life. Inexpert improvisation — plasticity — is arguably our default way of being-in-the-world. Now, we want to push this wide perspective even further by challenging HBA. We argue that a wide perspective highlights the extent to which everyday improvisation is very often a robustly distributed (i.e., beyond-the-head) affair, one that involves the ongoing integration of sensorimotor processes with environmental artifacts and institutions that we interact with on a day-to-day basis.

Most activities of everyday life are regulated by norm-governed practices and institutions that shape the structure and character of these actions. Shaun Gallagher (2013) terms these institutions "mental institutions". Mental institutions are networks of social practices, rituals, institutions, and norm-governed artifacts that give us access to novel abilities or features of the world that might otherwise remain beyond our reach. For Gallagher, mental institutions are significant because they both augment our cognitive capacities as well as present topdown constraints on our embodied "habits of mind" - our characteristic ways of attending to, interpreting, and engaging with the world - that shape our everyday acts of inexpert improvisation. Mental institutions have two core features: (1) they consist of cognitive artifacts and practices produced in specific times and places, and (2) they are activated in ways that extend our cognitive processes when we engage with them in the right sort of way (Gallagher, 2013, p. 6). These institutions come in many forms: from academic, scientific, legal, and religious institutions to broader cultural and economic practices. Gallagher's focus is on the way that mental institutions extend cognition insofar as they open up otherwise inaccessible cognitive processes. 
Forthcoming in Improvisation: The Competence(s) of Not Being in Control, eds. J. McGuirk, S. Ravn, and S. Høffding. Routledge

For example, Gallagher argues that some legal judgments - like evaluating the legitimacy of a specific claim - are only possible when individuals link up with artifacts and practices that make up the mental institution of law. This institution furnishes a rich array of beyond-thehead resources - contracts, systems of rights and laws, norm-governed procedures, precedence, etc. - that enable users to manipulate and work through vast amounts of information they couldn't otherwise process without this external cognitive support. Gallagher concludes that if we argue that cognition supervenes on individual artifacts like notebooks, maps, smartphones and microscopes (as extended mind theorists do), we ought to similarly grant cognitive status to beyond-the-head mental institutions designed specifically to augment our cognitive practices (Gallagher, 2013, p. 7).

Gallagher focuses on large-scale mental institutions like legal systems and academic research practices. But our lifeworlds are full of mental institutions that work at a more local level, too, local institutions regulate the dynamics of how we engage with others in a shared world. As we'll see, they also create spaces for everyday inexpert improvisation. For example, commuter trains, grocery stores, and cocktail parties are all examples of norm-governed institutions that regulate our behavior and social interactions. Of course, when we inhabit these institutions, we do not blindly follow rigid social scripts; there is, as we'll see, ample room for improvisation. But the key point is this: much of the practical knowledge we have of these institutions and how to negotiate them is carried not just by brain-based processes or internal "mentalizing" that allow us to attribute mental states to others. It is also carried by beyond-the-head artifacts and practices designed specifically to make us intelligible to one another as social agents (Zawidzki, 2013). These shared artifacts and practices, and the mental institutions they are part of, provide a unifying context that drives and regulates our moment-to-moment actions while also providing creative spaces for (inexpert) improvisation and expressive flexibility.

Some examples will help clarify this point. Consider how deeply our thought, feeling, and behavior are directly modulated by the artifacts, relationships, and norms - the local mental institutions - distinctive of the specific contexts we move through on a day-to-day basis. Our habits of mind are shaped by both internal and external constraints (Higgins, 2017). For example, without explicitly thinking about it, we seamlessly adopt different styles of 
Forthcoming in Improvisation: The Competence(s) of Not Being in Control, eds. J. McGuirk, S. Ravn, and S. Høffding. Routledge

speaking, gesturing, behaving, and expressing emotions as we move through different interpersonal contexts. If we're out for an evening of drinking and dining with friends, extravagant expressions of humor (e.g., big open-mouthed smiles; dramatic gestures; loud laughter, joking, etc.) are welcome within that mental institution and will enhance the atmosphere. However, these same embodied expressions will be perceived as disruptive in more formal contexts such as a professional meeting, a funeral, or place of worship. For the most part, we unreflectively adjust our bodily-expressive style to match the different environments and institutions we negotiate.

In a similar way, evaluative appraisals of salience are modulated by our interpersonal contexts and the institutions that organize these contexts. We attend to and interpret the world differently when out for a casual night with friends than we do when participating in a sporting event or political rally, or when trying to find our way around a new city for the first time. For example, one might notice and be more inclined to act on a dirty look from a stranger - or respond positively to a flirty glance — when buttressed by the encouragement of rowdy friends than when walking the streets alone; when touring the city with a friend who's an architectural historian, we will notice specific features of familiar buildings and built spaces in a way we won't without their presence; we perceive a lone figure approaching us while walking down a deserted street at night as more threatening than when passing the same figure in an empty office corridor during the day.

As these examples show, contextual differences in habits of mind are heavily modulated not just by internal but also environmental constraints: background forces, artifacts, norms, and expectations - features of mental institutions - that shape the dynamics of our bodily responses and patterns of appraisal and behavior as we negotiate these different environments. The fact that we are deeply vulnerable to manipulation by ecological constraints, often with our full awareness or consent, reinforces how deeply this process occurs. For example, unspoken gender norms that structure many everyday mental institutions nudge women to both expect and accept more frequent interruptions than their male counterparts (Hancock \& Rubin, 2015). ${ }^{8}$

\footnotetext{
${ }^{8}$ See Slaby (2016) and Maiese and Hannah (2019) for further treatments of how we are deeply vulnerable to ecological manipulation by institutions such as workplace cultures and neoliberal social, educational, and economic institutions, respectively. For a related discussion of how mental institutions may overlook or exclude
} 
Forthcoming in Improvisation: The Competence(s) of Not Being in Control, eds. J. McGuirk, S. Ravn, and S. Høffding. Routledge

For our purposes, the key point is that mental institutions are beyond-the-head resources that do social-cognitive work for us by guiding our context-appropriate behavior and rendering us intelligible to one another as social agents (Krueger, 2011, 2013). Crucially, we generally don't have to plan, puzzle over, or explicitly think about what we or others are doing in a specific context because many aspects of social understanding and behavior are carried by the institutions that organize these contexts. They are scaffolded by the norms and routines that regulate our embodied interactions and habits of mind, and which have their social significance built into them (McGeer, 2001). ${ }^{9}$

This scaffolding occurs on multiple timescales. On a synchronic basis, mental institutions provide the regulatory tracks upon which token episodes of behavior run and develop their normative character. Think of the local mental institutions governing actions that are part of playing games; lining up in the queue to board a train or plane; putting our menu on the table to indicate our readiness to order; taking a phone call in the quiet vestibule of the train to avoid irritating our fellow travellers; pausing in the conversation to let the other person finish their thought. For most individuals acting within these institutions, behavior that dramatically departs from context-specific normative expectations - e.g., talking loudly in a quiet area of the train, or taking a sip of water from a neighbor's water bottle — isn't a live option (van Dijk \& Rietveld, 2017). Mental institutions constrain the normative range of synchronic action-possibilities. However, ongoing interactions with mental institutions also shape the diachronic development of bodily practices and habits of mind that are responsive to these mental institutions. These habits become sedimented into our characteristic ways of engaging with the world. As Roeprstorff et al (2010) note, “certain models of expectancy come to be established, and the patterns, which over time emerge from these practices, guide perception as well as action" on both short- and long-term timescales (p., 1056).

So, how does all this relate to improvisation? For our purposes, two points are salient. First, as we've noted, much of the practical knowledge we use to negotiate the social world - and crucially, that we use to improvise - is not something we must carry around with us inside

individuals who don't fit certain normative expectations (e.g., people with autism), see Krueger (forthcoming) and Krueger and Maiese (2018).

${ }^{9}$ However, as we discuss below, this environmental regulation does not preclude possibilities for improvisation but instead creates space for it. 
Forthcoming in Improvisation: The Competence(s) of Not Being in Control, eds. J. McGuirk, S. Ravn, and S. Høffding. Routledge

our heads from one moment to the next. Again, it is housed in the world, at least partially realized within the norms, routines, artifacts, and patterned practices that make up the mental institutions of everyday life. When we walk into a new situation - imagine we've just started a new job and we're invited to a colleague's party — we need not expend significant cognitive energy trying to sort out what to do or how to do it. Instead, we offload part of that cognitive work onto the world (Risko \& Gilbert, 2016). The local mental institutions governing parties provide regulatory resources that provide this information for us. More formally, the artifacts and practices that make up our mental institutions both locally and globally convert computationally demanding folk-psychological tasks (e.g., making inferences about others' mental states, appropriate party conduct, etc.) into easier perceptuomotor tasks (jointly coordinating our behavior to shared rules of party-going, small talk, drinking, dancing, etc.) and, in so doing, reduces the descriptive complexity of that environment by guiding our attention to salient features of relevant norm-governed behavior. This mental institution in this way scaffolds our selective attention and guides our contextappropriate actions. It helps us skillfully negotiate this context without our having to internalize all the relevant practical information.

Second, while these institutions regulate our attention, behavior, and habits of mind, they don't strip us of all of our agency and autonomy. ${ }^{10}$ The fact that they do some of the socialcognitive work for us means that they also nevertheless create spaces for improvisation, creativity, and unique forms of self-expression. In other words, while mental institutions often scaffold our practical knowledge by telling us what to do and when and how to do it, we also find creative ways to improvise within these institutions. We do so because we don't have to overthink about what to do or when or how to do it; again, we let the institutions do much of this work for us. And this offloading, in turn, frees up creative resources for improvisation as we are synchronically and diachronically guided by the behavioral and attentional constraints set up by these institutions. Mental institutions may therefore provide a fixed set of environmental cues, prompts, practices, and artefactual resources that fill in the gaps in our practical knowledge. But as inexpert improvisers (in our sense of the term), we are nevertheless still free to improvise in terms of how and when we choose to exploit these resources - that is, how, exactly, we choose to use them in order to reach our goal. We

\footnotetext{
${ }^{10}$ Although their impact runs deep. See Maiese and Hanna (2019) for an extended critique of neoliberal mental institutions.
} 
Forthcoming in Improvisation: The Competence(s) of Not Being in Control, eds. J. McGuirk, S. Ravn, and S. Høffding. Routledge

remain attuned to these resources while using them to creatively attend, anticipate, and act in context-appropriate ways as situations dynamically shift and change (Sutton \& Bicknell, Forthcoming).

\section{Final thoughts}

In this chapter, we have argued against a narrow approach to improvisation, one that rests upon what we've termed the "uniqueness assumption" (UA) and "head-bound assumption" (HBA), respectively. We began by distinguishing two forms of improvisation: inexpert improvisation and expert improvisation. We explored this distinction by developing a series of considerations about intentional actions, intentions, and goals. We then turned to some empirical observations to further develop this distinction. We challenged a narrow approach to improvisation (and the two assumptions informing it) in two ways: first, we developed a "wide" alternative by showing how creativity and improvisation are not confined to unique or specialized domains but are instead central features of everyday life. Second, we argued that a wide perspective shows how everyday inexpert improvisation is very often a robustly distributed (i.e., beyond-the-head) affair, one that involves the ongoing integration of individuals with the various mental institutions - rich networks of norm-governed artifacts, rituals, practices, and institutions - that structure everyday life and forms of interpersonal relatedness. These mental institutions provide a unifying context regulating our moment-tomoment interactions while also providing creative spaces for inexpert improvisation and expressive flexibility. Based upon these considerations, we concluded that a comprehensive investigation of the phenomenon of improvisation should broaden its scope to include not only expert improvisation — which, while interesting, has limited relevance to everyday experience - and take a more focused look at inexpert improvisation, which is foundational to our social and cultural life.

So, where does this leave us? A key takeaway lesson from these "wide" considerations is that improvisation is, to use Ingold and Hallam's (2007) helpful phrase, “the way we work". If, as we've argued, improvisation is fundamental to everyday life, it seems "not just that life is unscripted, but more fundamentally, that it is unscriptable. Or, to put it another way, it cannot 
Forthcoming in Improvisation: The Competence(s) of Not Being in Control, eds. J. McGuirk, S. Ravn, and S. Høffding. Routledge

be fully codified as the output of any system of rules and representations" (p.12). To get through life the way that we do, we must remain open and responsive to continually changing environmental constraints. And this requires ongoing improvisation. However, as our discussion of mental institutions indicated, we set up our environments (and the resources within them) in ways that both animate and support this process across multiple timescales. These environments do not spring up fully formed. Instead, they develop over time as our social and cultural practices evolve and take shape. A properly "wide" perspective on improvisation would therefore account for these creative dynamics at the cultural level. In other words, it would investigate how our everyday practices of improvisation are produced, reproduced, refined, and reconfigured over many generations as individuals arise within environments set up to support the development of their improvisatory skills. But that is a project for another time. 
Forthcoming in Improvisation: The Competence(s) of Not Being in Control, eds. J. McGuirk, S. Ravn, and S. Høffding. Routledge

\section{References}

Agre, P. E., \& Chapman, D. (1987). Pengi: An Implementation of a Theory of Activity. Proceedings of the 6th National Conference on Artificial Intelligence, 87, 286-272. Aunger, R. (2000). Darwinizing Culture: The Status of Memetics as a Science. OUP Oxford. Bratman, M. (2014) Shared Agency. A Planning Theory of Acting Together. Oxford: OUP. Butterfill, S. A. (2013) Interacting Mindreaders. Philosophical Studies 165: 841-863.

Dewey, J. (1934/1980). Art as Experience. Perigree Books.

Dewey, J. (2008). Democracy and Education, The Middle Works of John Dewey, vol 9: 1916 (J. A. Boydston (ed.); Vol. 9). Southern Illinois University Press.

Gallagher, S. (2013). The socially extended mind. Cognitive Systems Research, 25-26, 4-12. Hancock, A. B., \& Rubin, B. A. (2015). Influence of Communication Partner's Gender on Language. Journal of Language and Social Psychology, 34(1), 46-64.

Higgins, J. (2017). Embodied Mind - Ensocialled Body: Navigating Bodily and Social Processes within Accounts of Human Cognitive Agency. Phenomenology and Mind, 12, $228-237$.

Høffding, S., \& Schiavio, A. (2019). Exploratory expertise and the dual intentionality of music-making. Phenomenology and the Cognitive Sciences. https://doi.org/10.1007/s11097-019-09626-5

Ingold, T., \& Hallam, E. (2007). Creativity and cultural improvisation: An introduction. In Creativity and cultural improvisation (pp. 1-24).

Krueger, J. (forthcoming). Enactivism, Other Minds, and Mental Disorders. Synthese, 1-25.

Krueger, J. (2011). Extended cognition and the space of social interaction. Consciousness and Cognition, 20(3), 643-657.

Krueger, J. (2013). Ontogenesis of the socially extended mind. Cognitive Systems Research, $25-26,40-46$

Krueger, J., \& Maiese, M. (2018). Mental institutions, habits of mind, and an extended approach to autism. Thaumàzein, 6, 10-41.

Linson, A., \& Clarke, E. F. (2017). Distributed cognition, ecological theory and group improvisation. In E. F. Clarke \& M. Doffman (Eds.), Distributed Creativity: Collaboration and Improvisation in Contemporary Music. Oxford University Press.

Maiese, M., \& Hanna, R. (2019). The Mind-Body Politic. Palgrave Macmillan.

McGeer, V. (2001). Psycho-practice, psycho-theory and the contrastive case of autism. How practices of mind become second-nature. Journal of Consciousness Studies, 8(5-6), 109- 
Forthcoming in Improvisation: The Competence(s) of Not Being in Control, eds. J. McGuirk, S. Ravn, and S. Høffding. Routledge

132.

McMahon, L. (2018). (Un)Healthy Systems: Merleau-Ponty, Dewey, and the Dynamic Equilibrium Between Self and Environment. The Journal of Speculative Philosophy, 32(4), 607-627.

Merleau-Ponty, M. (1963). The Structure of Behavior (A. L. Fisher, trans.). Duquesne University Press.

Risko, E. F., \& Gilbert, S. J. (2016). Cognitive Offloading. Trends in Cognitive Sciences, 20(9), 676-688.

Roepstorff, A., Niewöhner, J., \& Beck, S. (2010). Enculturing brains through patterned practices. Neural Networks: The Official Journal of the International Neural Network Society, 23(8-9), 1051-1059.

Salice, A. (2018) Practical Intentionality. From Brentano to the Phenomenology of the Munich and Göttingen Circles. In D. Zahavi (ed.) The Oxford Handbook of the History of Phenomenology. Oxford: Oxford University Press, 604-622.

Sassoon, R. (2000). The Art and Science of Handwriting. Intellect Books.

Sawyer, K. (2007). Improvisation and Teaching. Critical Studies in Improvisation / Études Critiques En Improvisation, 3(2). https://doi.org/10.21083/csieci.v3i2.380

Slaby, J. (2016). Mind Invasion: Situated Affectivity and the Corporate Life Hack. Frontiers in Psychology, 7(266), 1-13.

Sorrell, N. (1992). Improvisation. In J. Paynter, T. Howell, R. Orton, \& P. Seymour (Eds.), Companion to contemporary musical thought (Vol. 2, pp. 776-786). Routledge.

Sperber, D. (1996). Explaining Culture: A Naturalistic Approach (Illustrated edition). WILEY.

Sutton, J., \& Bicknell, K. (Forthcoming). Embodied Experience in the Cognitive Ecologies of Skilled Performance. In E. Fridland \& C. Pavese (Eds.), The Routledge Handbook of Skill and Expertise. Routledge.

Torrance, S., \& Schumann, F. (2019). The spur of the moment: what jazz improvisation tells cognitive science. AI \& Society, 34(2), 251-268.

van der Schyff, D. (2017). Improvisation, Enaction \& Self-Assessment. In D. J. Elliot, M. Silverman, \& G. McPherson (Eds.), The Oxford Handbook of Philosophical and Qualitative Perspectives on Assessment in Music Education. Oxford University Press.

van Dijk, L., \& Rietveld, E. (2017). Foregrounding Sociomaterial Practice in Our Understanding of Affordances: The Skilled Intentionality Framework. Frontiers in 
Forthcoming in Improvisation: The Competence(s) of Not Being in Control, eds. J. McGuirk, S. Ravn, and S. Høffding. Routledge

Psychology, 7(1969), 1-12.

Wittgenstein, L. (1958). Philosophical investigations. Trans., G. E. M. Anscombe. MacMillan Publishing Co., New York, NY.

Zawidzki, T. W. (2013). Mindshaping: A New Framework for Understanding Human Social Cognition. MIT Press. 